\title{
Development of HPTLC Method and Its Validation for the Estimation of Curcuminoids from Polyherbal Mouth Ulcer Gel Formulation
}

\author{
Safeena Sheikh, Suhail Asghar, Showkat Ahmad \\ Unijules Life Sciences Ltd, B - 35, 36 MIDC Area Kalmeshwar, Nagpur - 441501 (Maharashtra) India
}

\begin{abstract}
A rapid, simple, selective and precise high performance thin layer chromatographic method has been developed for the determination of curcumin in mouth ulcer poly herbal formulation. The separation was performed on TLC aluminium plates Precoated with silica gel G60 F254. Good separation was achieved in the mobile phase of Chloroform: methanol: Glacial acetic acid (7.5: 2.0: $0.5 \mathrm{v} / \mathrm{v} / \mathrm{v})$ at $\mathrm{Rf}=0.18,0.31,0.56$ for bisdemethoxy curcumin, demethoxy curcumin and curcumin respectively. The method was validated successfully by checking precision, repeatability and accuracy. The present method can simplify the analysis of Curcuminoids in poly herbal formulations for their routine quality analysis.
\end{abstract}

Keywords:- Curcuminoids, curcumin, demethoxy curcumin, bisdemethoxy Curcumin, method development, validation, stability, densitometry, Quantification.

\section{INTRODUCTION}

Turmeric Curcuma longa ${ }^{l}$ L. (Zingiberaceae) family is commonly known for its medicinal values in the Indian traditional system of medicine curcuma longa ${ }^{2}$ accelerates the process of ulcer healing and has anti

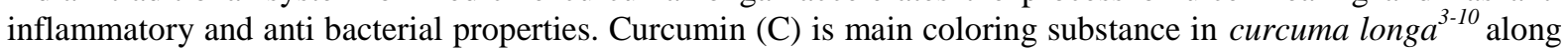
with the other two related compounds, demethoxy Curcumin (DMC) and bis demethoxy Curcumin (BDMC) are altogether known as Curcuminoids. The chemical structures of three Curcuminoids are shown in Figure.1.

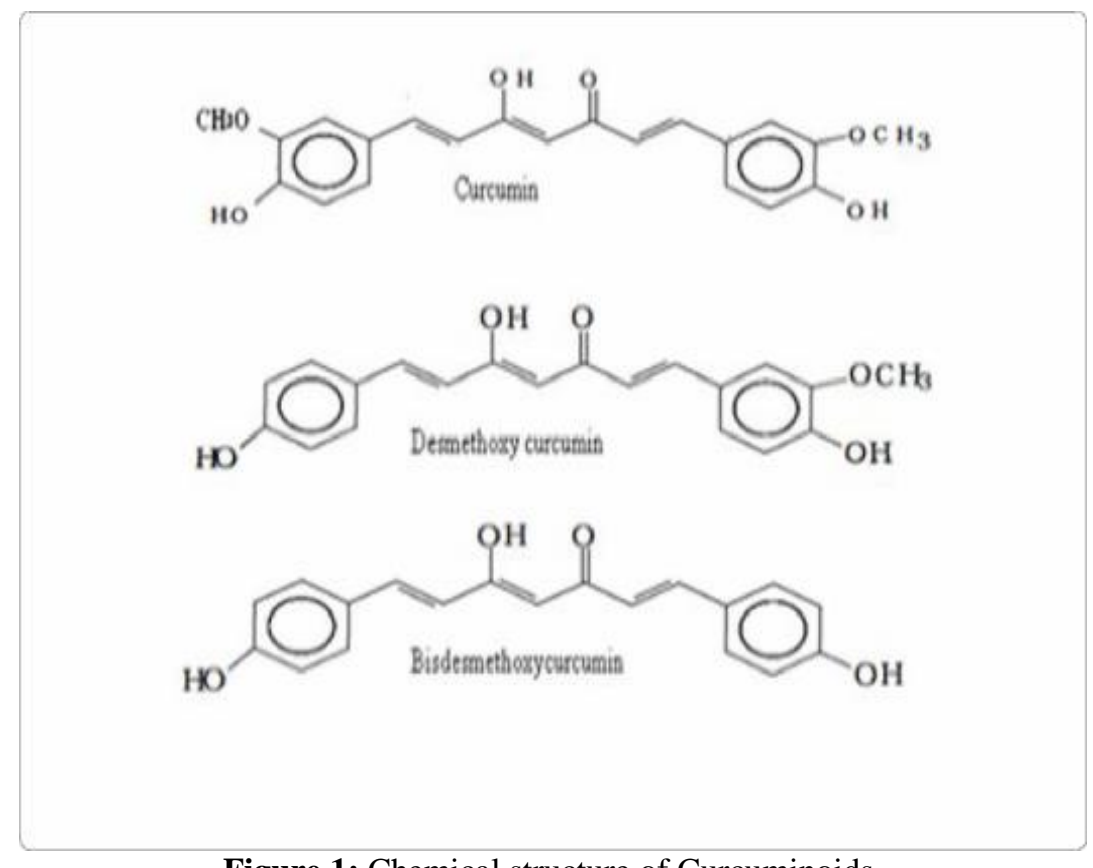

Figure.1: Chemical structure of Curcuminoids.

The pharmaceutical gel which is under taken for study contains Aloe vera and curcuma longa. A number of studies are undertaken to separate curcuminoids pigments by thin layer chromatography (TLC), High Performance thin layer chromatography ${ }^{11}$ (HPTLC), and column chromatography (CC). The stationary phase most commonly used is silica gel with different solvent systems including benzene, ethyl acetate, ethanol, chloroform, acetic acid, hexane, and methanol for chromatographic separations. HPLC ${ }^{12}$ method was sensitive, precise and accurate for detection and quantification of curcuminoids in the extract of rhizome Curcuma longa. 
Separation by high performance liquid chromatography ${ }^{15-21}$ (HPLC) was done mostly on reverse phase HPLC method employing mixtures of water, acetonitrile, ethanol, potassium dihydrogen phosphate buffer and methanol since the curcuminoids pigments vary in chemical structures, it is possible that the physico-chemical characteristics as well as the functional properties would vary among them. There are number of method are available for the estimation of curcuminoids from raw herb, their powder mixtures, and other ayurvedic formulations by HPTLC ${ }^{22-23}$ method of analysis but no method is available which describes the development and validations of curcuminoids from pharmaceutical poly herbal gel formulations.

\section{MATERIAL AND METHODS}

\section{Chemical, Equipments and Instrument:}

All chemicals and reagents of analytical grade were purchased from Merck chemical, Mumbai. India. Pure drug sample of Curcuminoids was kindly supplied as a sample from natural remedies labs. HPTLC system used for analysis was of CAMAG HPTLC system. The sample were spotted in the form of bands with a Camag 100microlite sample syringe (Hamilton, Bondouz, Switzerland) syringe on Precoated silica gel aluminium plate

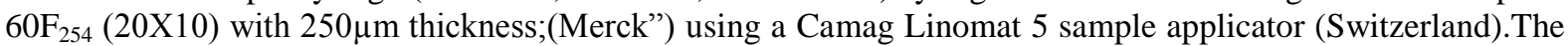
linear ascending development was carried out in $20 \mathrm{cmX} 10 \mathrm{~cm}$ twin trough chamber using mobile phase (Chloroform: methanol: Glacial acetic acid 7.5: 2.0: $0.5 \mathrm{v} / \mathrm{v} / \mathrm{v}$ ). TLC plates were dried on Camag TLC plate heater III.Densitometric scanning was performed on Camag TLC scanner 3 in the reflectance-absorbance mode at $430 \mathrm{~nm}$ after development for all measurement and operated by Camag WINCATS software. The source of radiation utilized was tungsten lamp emitting a continuous UV spectrum 400 to $700 \mathrm{~nm}$.

\section{Preparation of standard solution:}

Stock solutions of curcumin $(1 \mu \mathrm{g} / \mu \mathrm{l})$, demethoxy curcumin and Bisdemethoxy curcumin $(0.5 \mu \mathrm{g} / \mu \mathrm{l})$ were prepared in methanol and different concentrations were applied on TLC plate, Linomat $\mathrm{V}$ for preparing calibration curve.

\section{Sample preparation:}

Weigh accurately $10.0 \mathrm{gm}$ sample in $100 \mathrm{ml}$ beaker, add $30 \mathrm{ml}$ methanol and stir it for 10 minutes. Transfer the dissolved solution in to $50 \mathrm{ml}$ volumetric flask and again stir the remaining residue with $15 \mathrm{ml}$ methanol transfer the solution to same volumetric and make up the volume to $50 \mathrm{ml}$ with methanol.

\section{Optimization of the HPTLC method:}

It is well known that the solvent do exert a profound influence on the quality and shape of the peak; the chromatographic separation studies were carried out on the stock solution of curcuminoids. Initially on the plate $4.0 \mu 1$ of stock solution was applied as band $8 \mathrm{~mm}$ of width. Plates were developed by ascending development using neat solvents like hexane, acetone, ammonia, methanol, chloroform, dichloromethane, ethyl acetate, acetonitrile etc. without chamber saturation. Based on the results of these initial chromatograms binary and ternary mixtures of solvents were tried to achieve optimum resolution between Curcuminoids. After several trials mixture of Chloroform: methanol: Glacial acetic acid (7.5: 2.0: $0.5 \mathrm{v} / \mathrm{v} / \mathrm{v})$ was chosen as the mobile phase for analysis then the plate was at $60^{\circ} \mathrm{C}$ for 5 minute. The other chromatographic conditions like chamber saturation time, run length, sample application rate and volume, sample application positions, distance between tracks, detection wavelength, were optimized to give reproducible $\mathrm{Rf}$ value, better resolution, and symmetrical peak shape for the drugs. The spot appeared more compact and peak shape more symmetrical when the TLC plate were pretreated first with methanol and then with the mixture of chloroform and methanol $(1: 1 \mathrm{v} / \mathrm{v})$ after that the plate was activated at $110^{\circ} \mathrm{C}$ for 5.0 minutes.

\section{Calibration curve for curcuminoids:}

Different amounts of standard solutions were applied (band width: 6mm, distance between bands: $11.5 \mathrm{~mm}$, in triplicate on a Precoated silica gel 60 F 254 TLC plate using a CAMAG Linomat V semiautomatic applicator.

\section{Quantification of Curcuminoids in formulation:}

6.0 $\mu 1$ each of the sample solutions was applied on the same plate using a CAMAG Linomat V semiautomatic auto sampler along with standard. The plate was developed and scanned as mentioned above. The peak areas were recorded and amount of curcuminoids were calculated from the calibration curve.

\section{Method Validation:}

The method was validated ${ }^{14}$ for precision, repeatability and accuracy. Precision was checked by repeated scanning of the same spots of curcuminoids 6 times $(n=6)$ and was expressed as coefficient of variance 
$(\% \mathrm{CV})$. The repeatability of the method was affirmed by analyzing different concentration of curcuminoids in standard solution after application and TLC plate $(n=6)$ and was expressed as \% CV. Accuracy of the method was tested by performing recovery studies at three different levels. To preanalyzed samples of pharmaceutical poly herbal gel formulation, standard curcuminoids were added in the range of linearity in different amount and mean $\%$ recovery were calculated.

\section{RESULT AND DISCUSSION}

We report a method for the quantification of curcuminoids (i.e. curcumin, demethoxy curcumin and Bis demethoxy curcumin) in pharmaceutical herbal formulation. Of the various solvent systems tried, the one containing Chloroform: methanol: Glacial acetic acid (7.5: 2.0: $0.5 \mathrm{v} / \mathrm{v} / \mathrm{v})$ gave the best resolution of curcuminoids in the presence of other compounds present in the formulation. The identity of the bands in sample formulation was confirmed by overlaying their UV absorption spectrum with that of standards. Purity of the curcuminoids in the sample was confirmed by comparing the absorption spectra at start, middle and end position of the respective bands.

The method was validated in terms of precision, repeatability and accuracy. The relationship between the concentration and peak response was linear within the range of 500 to 5000ng/spot; 200 to 1200ng and 100700ng for curcumin, demethoxy curcumin and bis demethoxy Curcumin respectively.

The mean $\%$ recovery at three different levels for curcumin, demethoxy curcumin and bis demethoxy curcumin was found to be $100.80 \%, 99.23 \%$ and $100.12 \%$ for sample formulation respectively. The amount of curcuminoids in the formulation was estimated by the proposed method simultaneously.

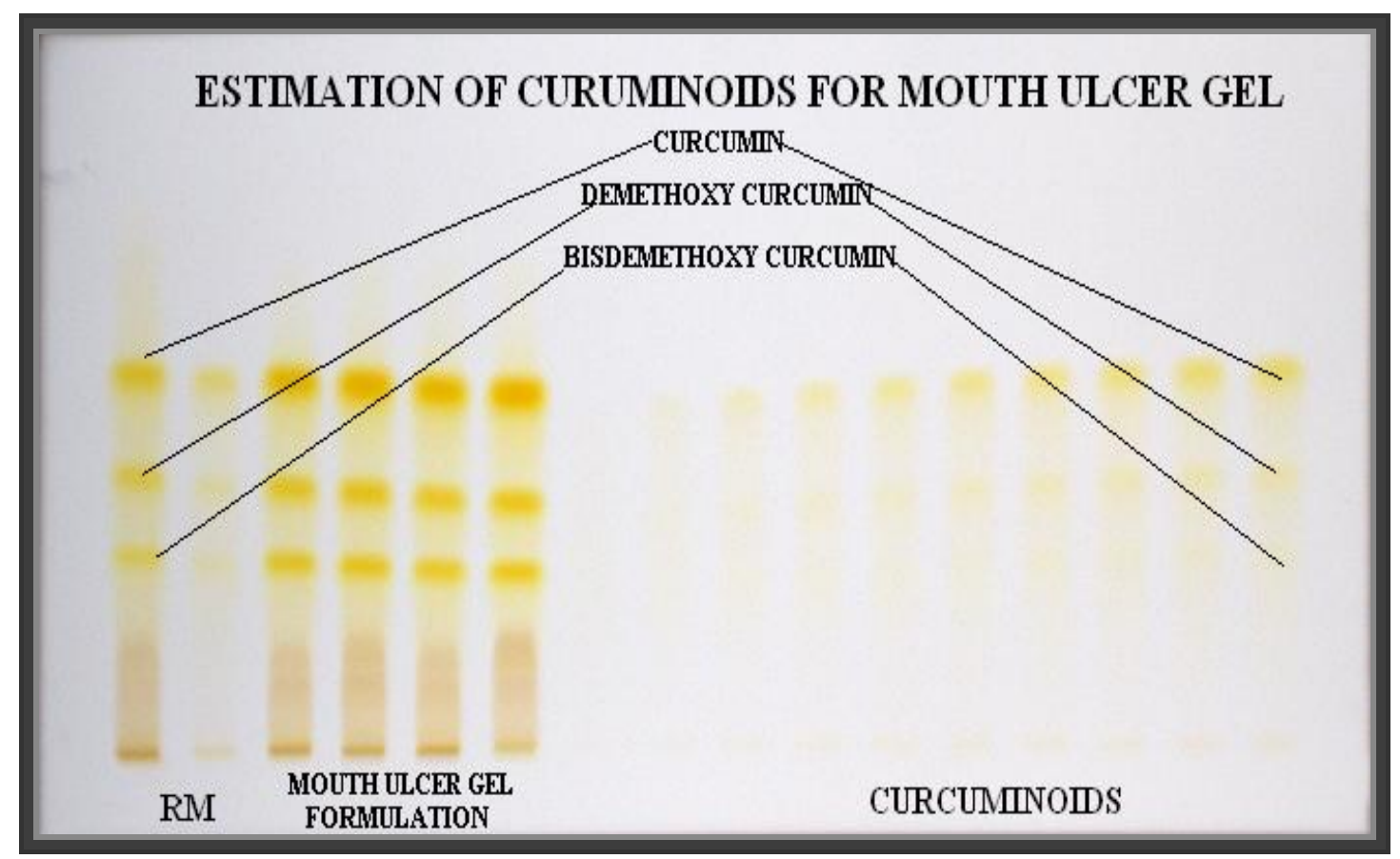

Figure2 (A) chromatogram showing the separated spots of curcuminoids mixture in raw material and in test sample corresponding to standard curcuminoids. 
Track 13, ID: Standard7

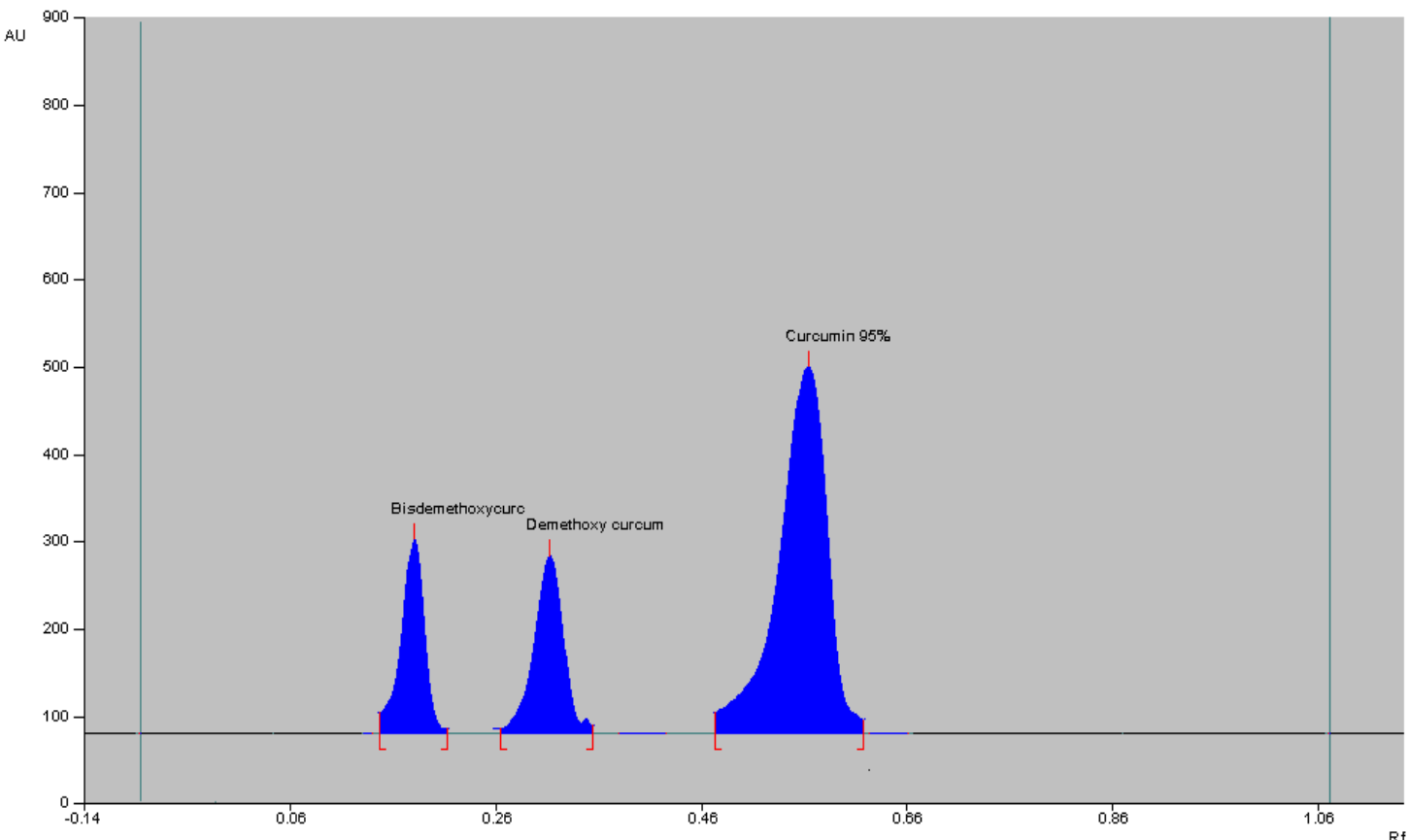

Figure 2(B): Shows densitogram of standard showing curcumin $\mathrm{R} f=0.18$, demethoxy curcumin $\mathrm{R} f=0.31$ and bisdemethoxy curcumin $\mathrm{Rf}=0.56$ at $430 \mathrm{~nm}$ in reflection/absorption mode simultaneously.

Track 2, ID: Product

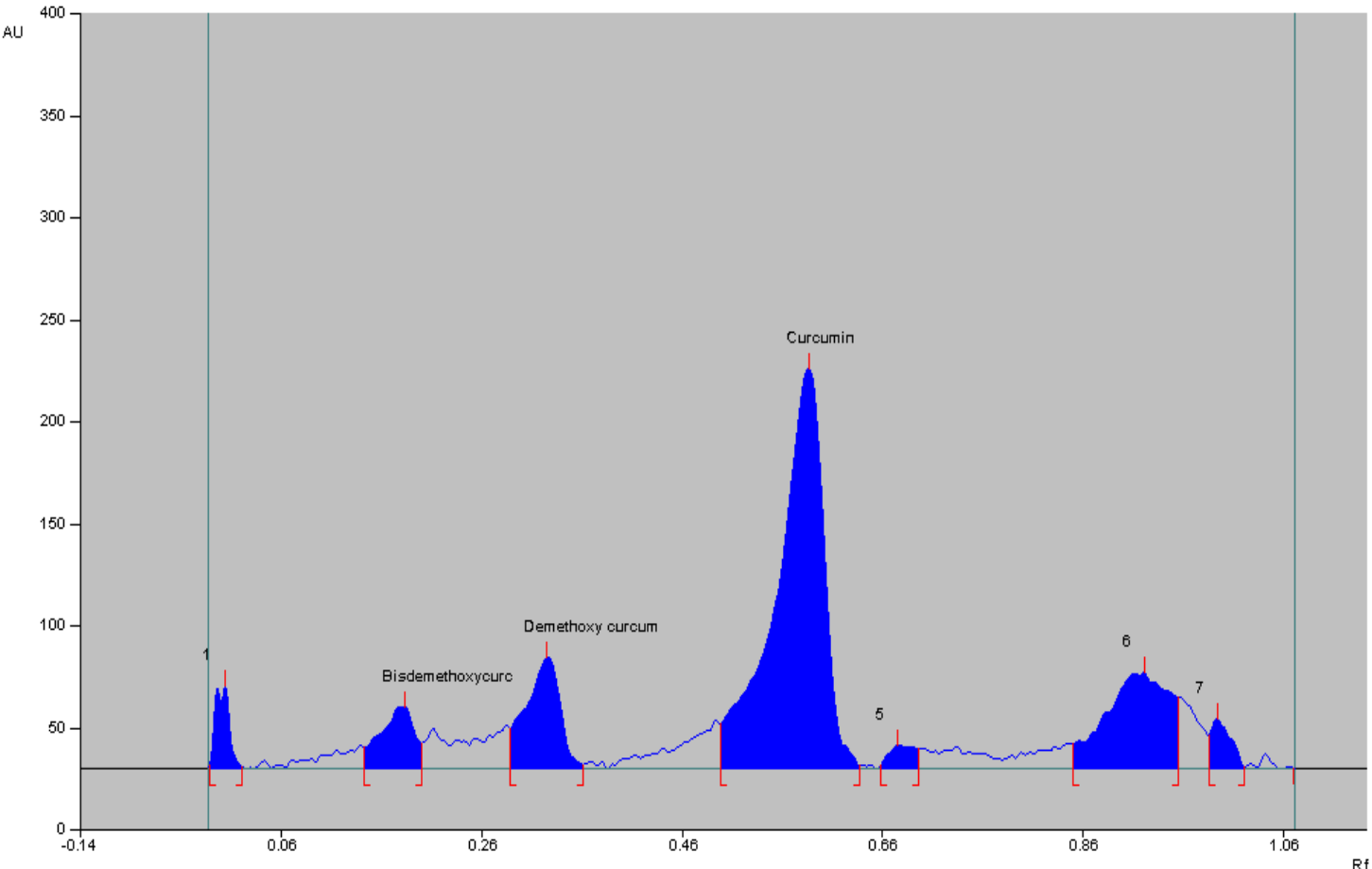

Figure 3: Shows densitogram of product showing curcumin, demethoxy curcumin and bisdemethoxy curcumin simultaneously. 
Table 1: Method Validation Parameters.

\begin{tabular}{|c|c|c|c|}
\hline Parameter & $\begin{array}{ll}\begin{array}{l}\text { Result } \\
\text { curcumin }\end{array} & \text { for } \\
\end{array}$ & $\begin{array}{l}\text { Demethoxy } \\
\text { curcumin }\end{array}$ & $\begin{array}{l}\text { Bisdemethoxy } \\
\text { curcumin }\end{array}$ \\
\hline $\begin{array}{l}\text { Precision } \\
(\% \mathrm{CV}, \mathrm{n}=6)\end{array}$ & 1.22 & 1.67 & 1.29 \\
\hline $\begin{array}{l}\text { Repeatability } \\
(\% \mathrm{CV}, \mathrm{n}=6)\end{array}$ & 1.26 & 1.58 & 1.63 \\
\hline LOD & $100 \mathrm{ng} / \mathrm{spot}$ & $45.0 \mathrm{ng} / \mathrm{spot}$ & $52.0 \mathrm{ng} / \mathrm{spot}$ \\
\hline LOQ & 250ng/spot & $170 \mathrm{ng} / \mathrm{spot}$ & $80.0 \mathrm{ng} / \mathrm{spot}$ \\
\hline $\begin{array}{l}\text { Linearity } \\
\text { (Correlation } \\
\text { coefficient) }\end{array}$ & $\begin{array}{l}\mathrm{Y}= \\
3505.107+50.275^{*} \\
\mathrm{X}\end{array}$ & $\begin{array}{l}\mathrm{Y}= \\
303.578+8.2584 * \mathrm{X}\end{array}$ & $\begin{array}{l}\mathrm{Y}= \\
603.108+12.0516 * \mathrm{X}\end{array}$ \\
\hline $\begin{array}{l}\text { Linearity range } \\
\text { (ng/spot) }\end{array}$ & 500 to $5000 \mathrm{ng} / \mathrm{spot}$ & 200 to $1200 \mathrm{ng}$ & 100-700ng \\
\hline Retention factor & 0.18 & 0.31 & 0.56 \\
\hline
\end{tabular}

Table 2: Precision data of Curcuminoids.

\begin{tabular}{|l|l|l|l|l|}
\hline \multirow{2}{*}{$\begin{array}{l}\text { Sr. } \\
\text { No. }\end{array}$} & $\begin{array}{l}\text { Application of } \\
\text { sample }(\boldsymbol{\mu l})\end{array}$ & \multicolumn{4}{|l|}{ Area of Standard } \\
\cline { 3 - 5 } & & Curcumin & $\begin{array}{l}\text { Demethoxy } \\
\text { Curcumin }\end{array}$ & $\begin{array}{l}\text { Bisdemethoxy } \\
\text { Curcumin }\end{array}$ \\
\hline 1 & 4 & 15870.95 & 4560.21 & 3544.25 \\
\hline 2 & 4 & 16262.46 & 4578.25 & 3606.59 \\
\hline 3 & 4 & 15860.46 & 4743.10 & 3548.54 \\
\hline 4 & 4 & 15980.78 & 4516.60 & 3550.42 \\
\hline 5 & 4 & 16300.67 & 4607.05 & 3566.45 \\
\hline 6 & 4 & 15931.08 & 4606.08 & 3661.45 \\
\hline Average & 16034.40 & 4601.88 & 3579.61 \\
\hline \% RSD & 1.22 & 1.67 & 1.29 \\
\hline
\end{tabular}

\section{CONCLUSION}

The HPTLC method developed was found to be suitable for the quantitation of curcumin, demethoxy curcumin and Bisdemethoxy curcumin in herbal mouth ulcer formulation in presence of other plant constituents and formulation excipients. The proposed method was found to be precise, simple, specific and sensitive and can be used for quality control purposes.

\section{REFERENCE}

\section{Books}

[1]. Ravindran P, babu KN, Sivaraman K. 2007. In; Turmeric the genus Curcuma, Boca 150-155.

[2]. Indian pharmacopoeia, Indian pharmacopoeia commission Ghaziabad: 2007, Vol-III, P-.

[3]. Kokate CK, "Practical Pharmacognosy", 2008, Edition-IV, Vallabh Prakashan, New Delhi, page no. 107-111.

[4]. Mukherjee PK, "Quality Control of Herbal Drugs", 2007, An Approach to evaluation of Botanicals, Published by Business Harizons New Delhi.

[5]. Mukherjee K.P., 2002; "Quality control of herbal Drugs", $2^{\text {nd }}$ Edition, Business Horizons, 2-14.

[6]. Patel B, "An Introduction to Analytical Method Development for Pharmaceutical Formulations", 6, 2008.

[7]. Rajpal V, "Standardization of Botanicals", 2002, Vol.-I, Published by Eastern publishers New Delhi, page no. 223-228

[8]. Rajpal V, "Standardization of Botanicals", 2005, Vol.-II, Published by Eastern publishers New Delhi, page no. 1- 10, 120-132.

[9]. Anonymous, 2002 Indian pharmacopoeia, revised new edition, published by Indian Drugs manufactures association 102-B, poonam chambers, Mumbai, Page no. 67, 69.

[10]. Anonymous, 2007a: Indian pharmacopoeia, Ministry of health and family welfare, Government of India, New Dehli, 1996, 1, 41-42, 143-145.

[11]. Gupta AP, Gupta MM, Kuma SJ. 1999. Simultaneous determination of curcuminoids in curcuma samples using high-performance thin layer chromatography. Liq Chromatogr Real Time 22:1561-9. 
[12]. Wisut Wichitnithad 2009. A simple Isocratic HPLC Method for the Simulataneous determination of curcuminoids in commercial Turmeric Extracts. Phytochem. Anal; 20: 314-319.

[13]. Sane R.T., 2002; "Standardization, quality control and GMP's for herbal drugs" Indian Drugs, Vol39(3), 184-190.

[14]. Anonymous, 1994: International Conference on the Harmonization, Draft guideline on validation of analytical for pharmaceutical availability, federal register, 1994,59,9750.

\section{Literature}

[15]. Sompol Paramapojn and Wandee Grisanapan., 2009. Free radical scavenging activity determination and quatitative analysis of curcuminoids in curcuma zedoaria rhizome extracts by HPLC method current science, vol. 97, 1069-1073.

[16]. Jayaprakasha GK, jaganmohan Rao L. Sakariah KK, 2002. Improved HPLC method for the determination of Curcumin, demethoxy Curcumin and bis demethoxy Curcumin.J Agric Food Chem 50.3668-72.

[17]. M.Madhava Naidu, Shyamala, Srinivas 2009. Simple HPLC Method for Resolution of curcuminoids with Antioxidant Potential. Journal of food Science vol. 74(4).

[18]. Dange Pratibha B., Walode S.G., Kekare V.A., Kulkarni M.B. HPLC method for simultaneous estimation of Curcumin demethoxy Curcumin and Bis demethoxy Curcumin in a dietry supplement formulation.

[19]. Dalapathi B Gugulothu and vandana B Patravale., A new stability indicating HPLC method for simultaneous determination of Curcumin and celecoxib at single wavelength: an application to nanoparticulate formulation.

[20]. Ahmed SM, Manhas L R, Verma V, Khajuria R K, "Quantitative Determination of four constituents of Tinospora sps. By a RP-HPLC -UV-DAD Method" in the plant from different Eco-Geographical regions of India, journal; of chromatographic Sciences, 44, 2006, 504-509.

[21]. Soni Himesh. et. al. qualitative and quantitative profile of Curcumin from ethanolic extract of curcuma longa.

[22]. A.P. Gupta, M.M.Gupta, Sushi Kumar, simultaneous determination of curcuminoids in curcuma samples using high performance thin layer chromatography, J.Liq. chrom .\& Rel technology.

[23]. Niraj Vyas, et.al. simultaneous estimation of Curcumin and piperine in their crude powder mixtures and ayurvedic formulation using high performance thin layer chromatography.

[24]. Gunja Srivastava, Suman, Rajiv Gupta., detection, evaluation and quantitative estimation of Curcumin in herbal products.

[25]. Revathy.S, Elumalai.S, merina Benny and Benny Antony 2011. Evaluation of curcuminoids in Turmeric Rhizome (Curcuma longa L.) collected from different places in India. Biosciences, Biotechnology Research Asia vol 8(1).

[26]. V.S Govindarjan., 1980. Turmeric- chemistry, Technology, and Quality. CRC Critical Review in food Science and Nutrition, 12(3), 199-301. 